\title{
Prostatitis incrustante: Caso clínico y revisión de la bibliografía
}

\author{
E. Serrano-Brambila, V. López-Sámano, G. Montoya-Martínez , F. Holguín-Rodríguez, \\ E. Maldonado-Alcaraz
}

Hospital de Especialidades CMNSXXI, Instituto Mexicano del Seguro Social. México

Actas Urol Esp 2006; 30 (3): 321-323

\section{RESUMEN}

PROSTATITIS INCRUSTANTE: CASO CLÍNICO Y REVISIÓN DE LA BIBLIOGRAFÍA

Presentamos un caso clínico de prostatitis incrustante, término que no se encuentra en la búsqueda hecha en MedLine. La cistitis alcalina incrustante se describió hace 70 años y son pocos los casos descritos desde entonces, la mayoría de ellos asociados a infección por Corynebacterium ${ }^{1}$. De hecho, consideramos que estas dos entidades son muy similares, excepto en lo que se refiere al órgano afectado. Ambas presentan síntomas urinarios causantes de irritación, orina alcalina y necrosis tisular por debajo de una capa de calcificación. Otra entidad descrita en 1993 es la pielitis incrustante, relacionada con pacientes con inmunodeficiencia, especialmente los receptores de trasplante renal y también asociada a bacterias ureolíticas. El tratamiento de la cistitis y la pielitis incrustantes puede incluir antibióticos específicos, acidificación urinaria y escisión endoscópica de las lesiones calcificadas.

Palabras clave: Prostatitis incrustante. Cistitis incrustante. Bacterias ureoliticas.

\section{ABSTRACT}

ENCRUSTED PROSTATITIS: CASE REPORT AND LITERATURE REVIEW

We report a case of encrusted prostatitis, term which is not found in MedLine search. Alkaline encrusted cystitis was described 70 years ago and few cases have been described since that time, most of them associated with Corynebacterium infection ${ }^{1}$ In fact, we find these two entities very similar, except for the organ affected. Both present irritative urinary symptoms, alkaline urine and tisular necrosis below a calcification layer. Another entity described in 1993 is encrusted pyelitis, related to patients with immunodeficiency, particularly those with renal transplantation and also associated with ureolytic bacteria. The treatment of encrusted cystitis an pyelitis may include specific antibiotics, urinary acidification and endoscopic excision of the calcified lesions.

Keywords: Encrusted prostatitis. Encrusted cystitis. Ureolytic bacteria.

$\mathrm{E}_{\mathrm{r} e}^{1}$ término prostatitis incrustada no ha sido reportado hasta ahora en la literatura, sin embargo hay otras enfermedades con las que tiene ciertas similitudes clínicas y bioquímicas como es el caso de la cistitis incrustada.

La cistitis incrustada es una entidad infrecuente que consiste en un proceso inflamatorio intravesical, con precipitación e incrustación de sales de fosfato, carbonato y amonio-magnesio en la mucosa. El término cistitis alcalina incrustada fue descrito desde hace 70 años, y desde entonces, pocos casos han sido reportados. La patogénesis en la cistitis incrustada está determinada por la existencia de mucosa vesical dañada, infección urinaria por microorganismos urealíticos y orina alcalina que favorecen las incrustaciones $^{1}$.

Entre los microorganismos que favorecen el desarrollo de la cistitis incrustada tiene un lugar especial el Corynebacterium del grupo D, el cual se ha encontrado en la mayoría de los casos de esta enfermedad. El Corynebacterium del grupo D actúa en la fase inicial de la enfermedad dañando la mucosa vesical secundario a la rápida acción de la ureasa de la bacteria sobre el urotelio ${ }^{2}$.

Clínicamente la presencia de orina turbia de olor fuerte, $\mathrm{pH}$ alcalino y cristales de de amoniomagnesio-fosfato deben hacer sospechar la presencia de cistitis incrustada ${ }^{1}$.

Cistoscópicamente la cistitis incrustada se caracteriza por mucosa congestiva, edematosa y en ocasiones sangrante que se asocia con placas calcificadas; cuya reacción inflamatoria adyacente a las placas de calcificación puede ser tan intensa que semeja un tumor vesical. Cuando se asocia a Corynebacterium las calcificaciones tienden a ser lineales ${ }^{3,5}$. 
Han sido reportados casos de cistopatía incrustada posterior a resección de cáncer vesical y a uso de mitomicina $\mathrm{C}$, pero la relación causa-efecto no ha sido bien establecida ${ }^{3,4,6}$.

Los errores en los diagnósticos pueden ser posibles como en el caso de tumores calcificados por lo que la biopsia es esencial para establecer tal diagnóstico.

El tratamiento se basa en tres premisas fundamentales: La resección de la placa calcificada, la esterilización de la orina y la acidificación urinaria ${ }^{4}$.

Se han descrito complicaciones relacionadas directa o indirectamente con la cistitis incrustada, como daño al tracto urinario superior, insuficiencia renal, hematuria recurrente con anemia, capacidad vesical disminuida e incontinencia ${ }^{7}$.

La prostatitis incrustada a pesar de no haber sido descrita pareciera tener el mismo mecanismo patogénico que los casos de cistitis incrustada, teniendo como factores determinantes el daño tisular, orina alcalina y una infección por microorganismos productores de ureasa ${ }^{8}$.

Describimos el primer caso de prostatitis incrustada hasta ahora en la literatura médica.

\section{CASO CLÍNICO}

Se presenta el caso de un varón de 68 años con antecedentes de PSA de $9 \mathrm{ng} / \mathrm{ml}$, una serie de biopsias prostáticas negativas y RTUP dos años antes de su llegada a nuestro servicio. Tras la intervención se apreció hemorragia posoperatoria que requirió el taponamiento del hueco prostático y el ingreso en la unidad de cuidados intensivos. El material utilizado en el taponamiento prostático se retiró a las 72 horas y la sonda transuretral a los 14 días. En los meses siguientes el paciente refirió disuria intensa, polaquiuria, nocturia, hematuria leve intermitente e incluso hiperuricuria (10 episodios cada mes). Su calidad de vida estaba notablemente afectada ya que tenía ideas de suicidio.

$\mathrm{El}$ análisis de orina mostró persistentemente un $\mathrm{pH}$ alcalino (8-9), positividad para nitratos e innumerables hematies y leucocitos, aunque los cultivos de orina eran negativos. La creatinina y los parámetros hematológicos eran normales. El PSA era de $7 \mathrm{ng} / \mathrm{ml}$. El cistouretrograma mostró una imagen radiopaca irregular delimitando el espacio prostático; la uretra y la vejiga eran normales
(Fig. 1). Esta imagen parecía hiperecoica con sombra acústica posterior en la ecografía. La tomografía computarizada mostraba una pa-red vesical gruesa y una próstata irregular hiperdensa.

Se realizó una cistoscopia hallándose múltiples calcificaciones irregulares adheridas y limitadas a la próstata así como hiperemia mucosal intensa de la vejiga.

Se procedió a realizar una resección transuretral del tejido calcificado (Fig. 2). La sonda Foley se retiró 24 horas después de la intervención obteniéndose alivio casi inmediato de los síntomas. El informe anatomopatológico de más de 10 g de tejido mostró: Hiperplasia fibroadenomatosa, prostatitis crónica y aguda con abscedación y extensas áreas de necrosis e infarto. El análisis cristalográfico, hecho en dos laboratorios diferentes, determinó la presencia de un $60 \%$ de fosfato amónico magnésico hexahidratado (estruvita), $30 \%$ de uratos de amonio y $10 \%$ de hidroxiapatita y cabonato-apatita en el primero de los análisis y un $90 \%$ de uratos de amonio y $10 \%$ de fosfato amónico magnésico hexahidratado en el segundo (Fig. 3).

Tras 12 meses de seguimiento el paciente continúa asintomático. El análisis de orina muestra un $\mathrm{pH}$ de 5 , sin nitratos ni hematuria o leucocituria. Los cultivos de orina son negativos.

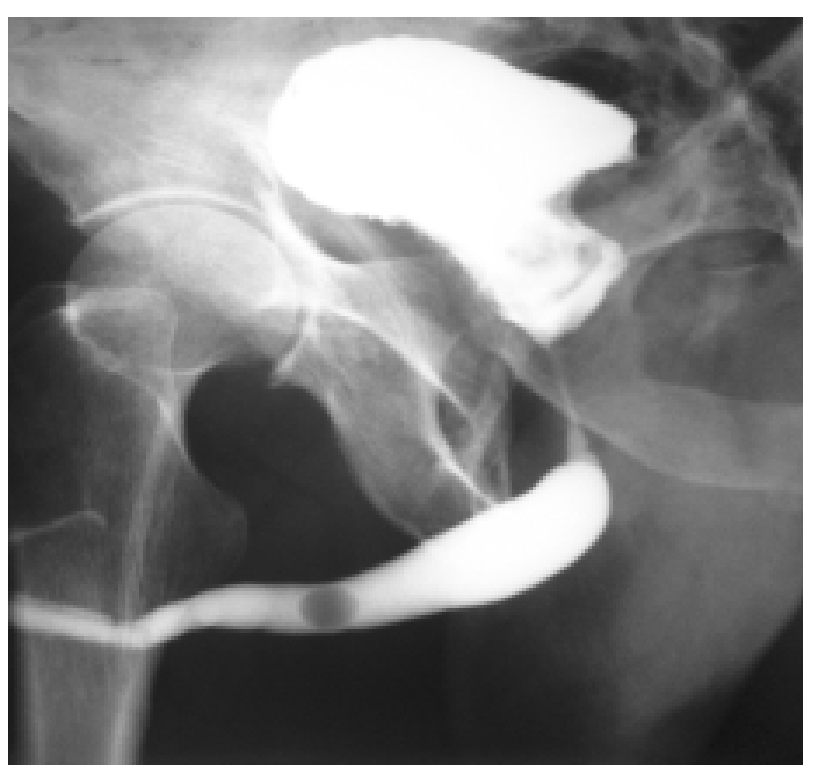

FIGURA 1. Cistouretrografia mostrando el hueco prostático calcificado. 


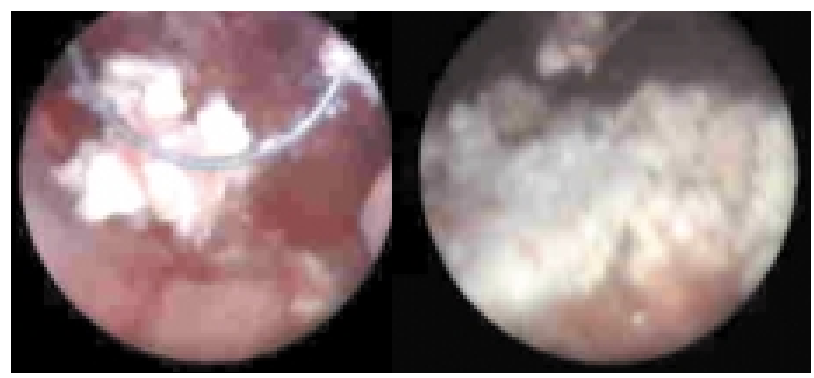

FIGURA 2. Resección de las incrustaciones.

\section{DISCUSION}

Probablemente, este es el primer caso de prostatitis incrustante comunicado en la bibliografía. Su patogenia es similar a la observada en la cistitis incrustante y la pielitis incrustante que son, sin duda, entidades muy raras. Existe un proceso inflamatorio urotelial intenso secundario a una infección de las vías urinarias debido a microrganismos ureolíticos como Corynebacterium del grupo D y precipitación e incrustación mucosal de sales de fosfato, carbonato y amonio-magnesio que se producen en un $\mathrm{pH}$ alcalino (8). En estas circunstancias, los pacientes se quejan de síntomas irritantes en las vías urinarias bajas y orina fétida. También tienen $\mathrm{pH}$ urinario alcalino y fosfato amónico magnésico en el examen cristalográfico ${ }^{2,3}$.

En este caso concreto, es probable que la reintervención de la próstata y el taponamiento en abierto fuesen decisivos para producir la necrosis extensa y la infección por gérmenes ureolíticos, dando lugar a la incrustación de las sales; en cualquier caso, no fue posible demostrar infección en los cultivos de orina comunes.

Según los mismos autores, se necesitan tres factores para producir una incrustación de minerales: Bacterias desintegradoras de urea capaces de producir amonio, alcalinización secundaria de la orina y lesión inflamatoria con independencia de la causa ${ }^{4}$.

Se han publicado algunos casos de cistitis tras resección transuretral de tumores de la vejiga. En estos casos prevalecen los síntomas urinarios molestos y la cistoscopia muestra una mucosa de la vejiga edematosa, congestiva y hemorrágica en asociación con una infección por Corynebacterium $^{3,5,6}$. Su tratamiento incluye la resección de las placas calcificadas y la esterilización y acidificación de la orina ${ }^{7,8}$.

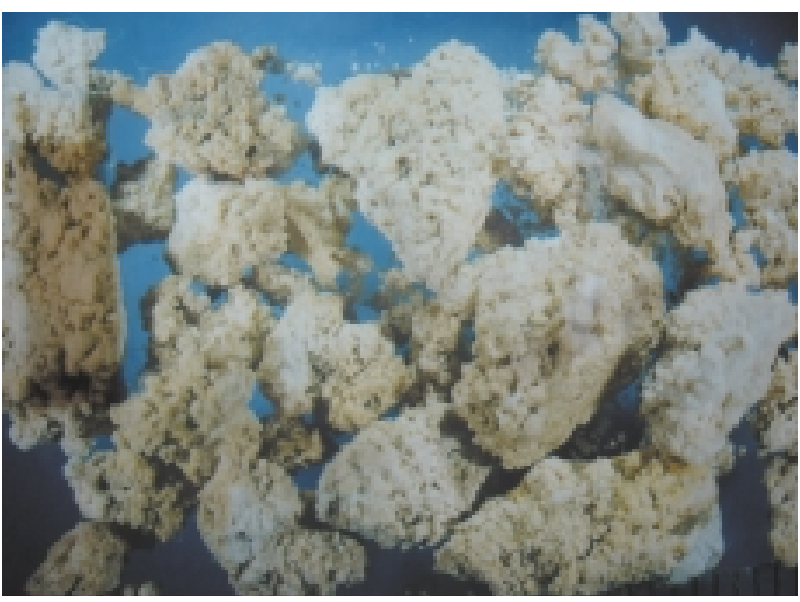

Figura 3. Incrustaciones después de la resección.

En este caso, la resección del tejido calcificado y el uso profiláctico de antibióticos fueron suficientes para aliviar las molestias del paciente.

\section{REFERENCIAS}

1. Fernandez-Natal MI, Garcia-Diez F, Salas-Valien JS, Cachon Garcia F, Soriano-García F. Incrusted cystitis with isolation of Corynebacterium group D2. Med Clin (Barc). 1992;98(11):419-422.

2. Sofras F, Yiannopoulou K, Kostakopoulos A, Dimopoulos C. Corynebacterium-induced cystitis with mucosal incrustrations. J Urol 1988;139(4):810.

3. Gonzalez-Enguita C, Montero-Rubio R, Cancho-Gil MJ, Crespi-Martinez F, Bravo- Fernandez, Barat-Cascante A, Vela-Navarrete. Acute and immediate urination syndrome after transurethral resection: a case of incrustating cystopathy.Actas Urol Esp 2003;27(1):47-54.

4. Romero-Perez P, Amat-Cecilia M, Omera-Arbash AR, Andrada-Becerra E. Acute scrotal hematoma in SchoenleinHenoch purpura. Infrequent urologic manifestation. Actas Urol Esp 1997;21(5):489-493.

5. Lliopis M, Moreno J, Botella R, Algado M. Incrusted cystitis after intravesical mitomycin C treatment. Acta Urol Belg 1993;61(3):21-23.

6. Masson JC, Charriere D, Masson J, Variani JP. Corynebacteria D2 and encrusted cystitis with alkaline urine. Prog Urol.1992;2(6):1012-1017.

7. Aubert J , Dore B, Touchard G, Loetitia G. Alkaline-urine incrusted cystitis. Clinical aspects and treatment. J Urol (Paris) 1982;88(6):359-363.

8. Maciejewski C, Boyer L, Carrie D, Ravel A, Boiteux JP, Giraud B, Viallet JF. Parietal calcifications of the kidney pelvis in Corynebacterium urealyticum urinary infection. J Radiol 1996;77(8):571-573.

Dr. E. Maldonado-Alcaraz

E-mail: urologia_maldonado@yahoo.com.mx

(Trabajo recibido el 31 de mayo 2005) 